\title{
Weld Geometry Investigation on Dissimilar Boron Steel Laser Welded for TWB Application
}

\author{
M. N. M. Salleh ${ }^{1}$, M. Ishak ${ }^{1,2^{*}}$, M. H. Aiman $^{1}$, M. M. Quazi ${ }^{1}$ and A. M. Hanafi ${ }^{1}$ \\ ${ }^{1}$ Faculty of Mechanical and Automotive Engineering Technology, Universiti Malaysia \\ Pahang, 26600 Pekan, Pahang, Malaysia \\ ${ }^{2}$ Automotive Engineering Centre, Universiti Malaysia Pahang, \\ 26600 Pekan, Pahang, Malaysia \\ *Email: mahadzir@ump.edu.my
}

\begin{abstract}
The pulse wave (PW) mode is an excellent replacement for continuous wave $(\mathrm{CW})$ mode of laser welding in the tailor-welded blank (TWB) application for the automotive industry. Due to its ability to produce higher peak power in low power laser pulse mode, the weld penetration and high weld quality can be achieved similarly to the utilization of a very high power laser of $\mathrm{CW}$ mode. This present work was carried out to investigate the effect of pulse laser welding parameters of a dissimilar thickness of boron steel for the TWB application. Low power fibre laser with $200 \mathrm{~W}$ average power was chosen in this experimental work. Response surface method (RSM) was used for the design of experiment (DOE) by applying Box-behnken design (BBD) since there were three process factors involved. The process factors are peak power (PP), welding speed (WS) and focal position (FP) and tensile strength is the response for the weld joint. The metallurgical analysis was conducted at the cross section of sample possessing highest and lowest tensile strength. Boron steel was successfully welded by using low power fibre laser with PW mode in butt joint configuration. It was found that the highest tensile strength possessed fracture located at the base metal, which is convincing the strength of the joint. For microstructure, finer grain produced at the centre of the fusion zone (FZ) compared to the FZ near the transition line which produced coarser and medium grain. Finer grain size in FZ contributes to the higher microhardness value and tensile strength of the joint compared to the BM region.
\end{abstract}

Keywords: Pulse wave mode; fibre laser; boron steel; TWB; dissimilar thickness

\section{INTRODUCTION}

Joining process is one of the important processes in manufacturing engineering, especially to join metal. Joining product has become a huge demand where it is vital to combine similar or different parts to become one product with excellent mechanical characteristics. Bolt and fasteners, adhesive, solder, rivet and welding are considered as joining methods. Welding method gives better result especially on joint strength in metal joining compared to the other joining processes due to the bonding between metals occurred at their original boundary surfaces [1]. The advancement of welding technology has been rose rapidly in order to improve the strength of metal joining [2]. Dissimilar welding is a term that is also familiar in welding technology. There are several types of dissimilar welding such as different materials, element content, and thickness. In this case, the dissimilar thickness of the material was selected to correlate with the tailor 
welded blanks (TWB) applications. TWB application consisted of two or more sheets which possess variation in dimensions [3]. Laser welding was widely used to produce the TWB products such as, A-pillar, B-pillar, roof reinforcement, and others parts [4].

In recent years, application of laser in material processing is increasing since it was introduced from 1960 [5]. This contribution includes the laser welding process to join metals where this method can be used to weld thin sheets metal [6]. A sound weld can be achieved by a consistent continuous wave $(\mathrm{CW})$ mode of laser welding process.

Assuncao and Williams [7] claimed that PW mode produced higher peak power and cooling rate compared to the $\mathrm{CW}$ mode. However, the weldability in term of weld geometry might be influenced by the entire parameter selection [8]. The characteristics of aspect ratio are required in detail to determine the weldability of welded joint [9]. Previously, laser welding studies were focused on material with similar thickness or similar material $[6,10,11]$. However, high complexity of laser parameters used for different thicknesses possessed different sets of parameters [12].

Nowadays, the TWB products in automotive parts use advanced high strength steel (AHSS) for the high strength result, which could increase the factor of safety in a car frame. Boron steel was selected in this experiment where the weld geometry and metallurgy were studied based on the low and high tensile strength joint. This current work was carried out to investigate the effect of pulse laser welding parameters on the mechanical properties of different thickness of Boron steel for the TWB application. The vital process factors which play a major role in this experiment were pulsed laser energy, welding speed, and angle of irradiation. The aspect ratio based on the weld geometry was also studied and related to the welding metallurgy. These parameters were primarily investigated in terms of microstructure behaviour after being laser welded.

\section{EXPERIMENTAL SETUP}

\section{Material Confirmation and Preparations}

In the present work, boron steel with $1.2 \mathrm{~mm}$ and $1.6 \mathrm{~mm}$ thickness was used as the base metal. The chemical composition of boron steel used was identified by using the spectrometer. Table 1 shows the chemical composition from the spectrometer test result for both boron steels where the percentage of B element is $0.002 \mathrm{wt} . \%$.

Table 1. Chemical composition of boron steel at dissimilar thickness.

\begin{tabular}{lcccccccc}
\hline Specimen & \multicolumn{8}{c}{ Element (wt.\%) } \\
& $\mathrm{C}$ & $\mathrm{Zn}$ & $\mathrm{P}$ & $\mathrm{S}$ & $\mathrm{Si}$ & $\mathrm{Al}$ & $\mathrm{Ti}$ & $\mathrm{B}$ \\
\hline Boron steel $(1.2 \mathrm{~mm})$ & 0.14 & 1.13 & 0.009 & $<0.003$ & 0.091 & 0.031 & $<0.002$ & 0.002 \\
Boron steel $(1.6 \mathrm{~mm})$ & 0.13 & 1.21 & 0.007 & $<0.003$ & 0.106 & 0.026 & 0.003 & 0.002 \\
\hline
\end{tabular}

For the welding process, the specimens were prepared according to the butt joint configuration for the tensile test sample dimension (ASTM E8) as shown in Figure 1. The coating was removed by $10 \mathrm{~mm}$ from each end of samples before the laser welding process initiated. Before the welding process was carried out, the coating from the steel has been removed from the surface using 180 grit sandpaper and then cleaned using Ethanol to remove any contaminant on the boron steel surface. The purpose of removing the coating was to increase the laser efficiency and specimen absorptivity. 
A flat and smooth weld surface was required for the welding process, as the butt joint gap clearance was critical due to the small laser beam size. The flat, squared edges and zero-gap clearance would result in the right consistency of the laser welding process. A vertical milling machine smoothened the edges of the sample with facing tools. At the same time, the welding direction needs to be perpendicular to the extrusion line of material to obtain a stable weld cross-section at the centre of the welded sample. After the welding was done, three tensile samples from each welded specimen were subjected to the tensile test, and the average tensile strength was calculated. The cross-section was selected at the centre of the weld region, as shown in Figure 1. ASTM E8 (sub-size) was selected for the tensile test sample.

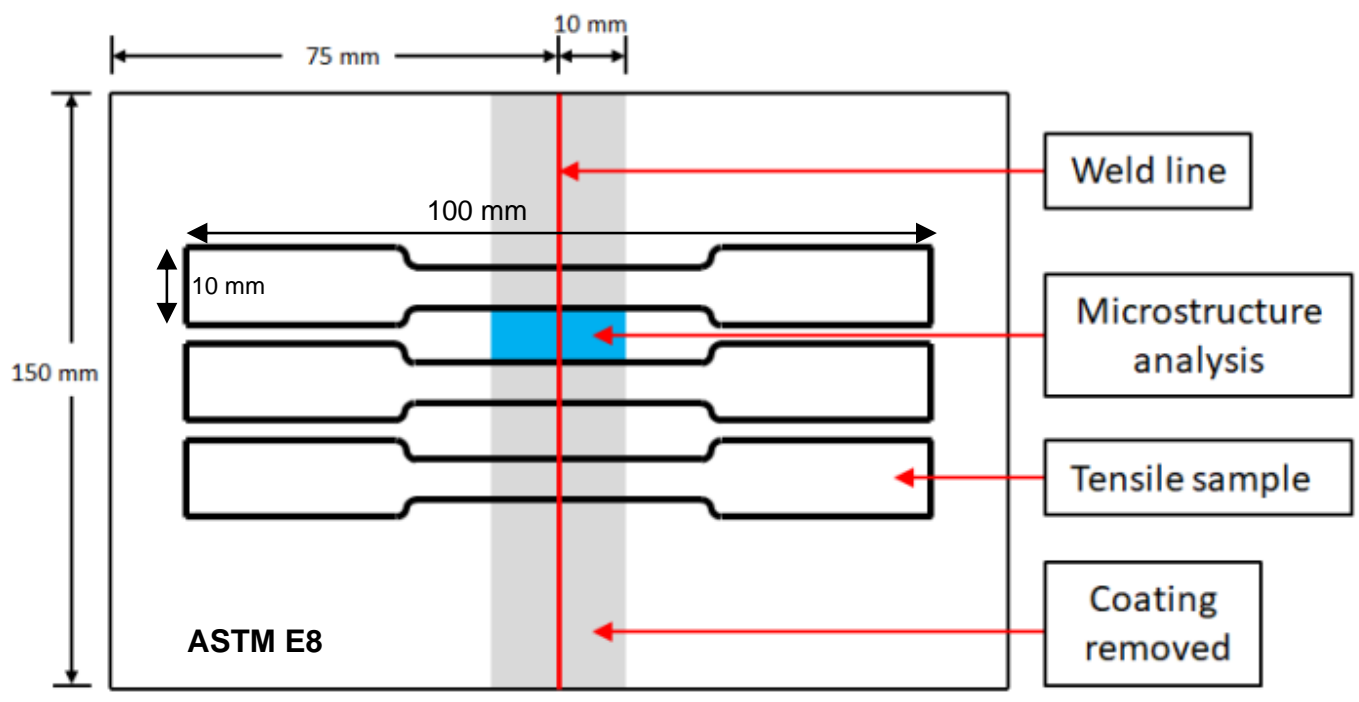

Figure 1. Butt joint configuration with the section for weld geometry.

\section{Experiment Setup}

The experiment was conducted using IPG YLM 200/2000 - quasi-continuous wave (QCW) fibre laser machine. This laser has a Q-switching feature which consists of continuous wave $(\mathrm{CW})$ and pulse wave $(\mathrm{PW})$ modes. The maximum average power for the $\mathrm{CW}$ mode is $0.2 \mathrm{~kW}$ and maximum peak power $\left(\mathrm{P}_{\mathrm{P}}\right)$ for the $\mathrm{PW}$ mode is $2 \mathrm{~kW}$. The laser head was equipped with the incident angle mechanism in order to avoid the direct reflection of the beam towards the lens. The laser head was attached on a custom-made machine which consists of three-axis movements which are $\mathrm{xy}$, and $\mathrm{z}$-axis. Figure 2 shows the schematic illustration for the laser welding setup.

The movement of the axis was controlled by using Arduino microcontroller. The custom welding jig was fixed on the $\mathrm{x}$-axis stage to ease the welding process. The shielding gas was supplied with custom made side-blown configuration by $6 \mathrm{~mm}$ diameter of the copper nozzle. Table 2 shows the parameters used in this experiment. The angle of the shielding gas nozzle was fixed to $30^{\circ}$ with $15 \mathrm{~L} / \mathrm{min}$ Argon gas and the laser head angle was fixed at $5^{\circ}$ of an incident angle as shown in Figure 2(a). Figure 2(b) shows the welding setup from the side view where the beam centre was positioned at the edge of each metal surface. The variable parameters were peak power, welding speed, and focal length, as shown in Table 2. For a systematic experimental order, a set of DOE table was constructed using Box-Behnken design (BBD) from the response surface method (RSM). Set of welding parameters is shown in Table 3. After being welded, all samples were 
subjected to a tensile test. Samples with lowest and highest tensile strength would be selected, and the results of weld geometry and microstructure would be compared.

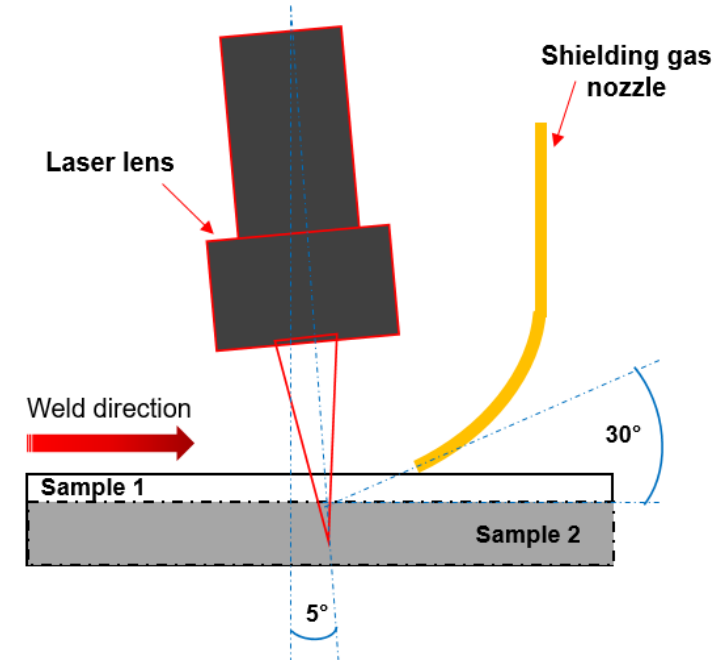

(a)

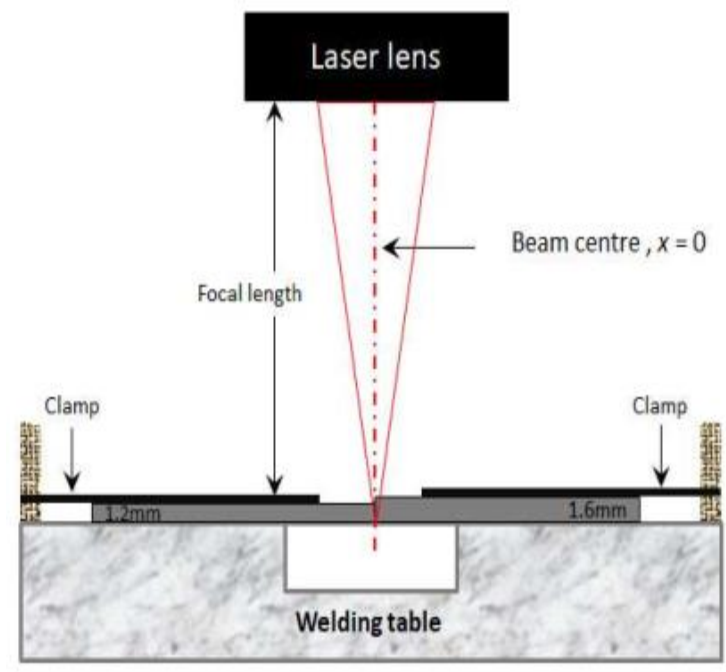

(b)

Figure 2. Schematic illustration of welding condition setup (a) front view (b) side view.

Table 2. Fibre laser welding parameters.

\begin{tabular}{lccc}
\hline & Parameter & Minimum & Maximum \\
\hline Variable & Peak Power (Watt) & 400 & 500 \\
& Welding Speed (mm/s) & 2.33 & 2.83 \\
\multirow{3}{*}{ Fixed } & Focal Length, F (mm) & 144 & 152 \\
& Incident angle & Laser head angle of 5 & \\
& Shielding gas & Argon gas, 30 $0^{\circ}$ angle, 15 L/min \\
\hline
\end{tabular}

Table 3. Set of welding parameters based on Box-Behnken design from RSM.

\begin{tabular}{lccc}
\hline Experiment no. & Peak power $(\mathrm{W})$ & Welding speed $(\mathrm{mm} / \mathrm{s})$ & Focal position $(\mathrm{mm})$ \\
\hline 1 & 400 & 2.33 & 148 \\
2 & 500 & 2.33 & 148 \\
3 & 400 & 2.83 & 148 \\
4 & 500 & 2.83 & 148 \\
5 & 400 & 2.58 & 144 \\
6 & 500 & 2.58 & 144 \\
7 & 400 & 2.58 & 152 \\
8 & 500 & 2.58 & 152 \\
9 & 450 & 2.33 & 144 \\
10 & 450 & 2.83 & 144 \\
11 & 450 & 2.33 & 152 \\
12 & 450 & 2.83 & 152 \\
13 & 450 & 2.58 & 148 \\
14 & 450 & 2.58 & 148 \\
15 & 450 & 2.58 & 148 \\
\hline
\end{tabular}




\section{RESULTS AND DISCUSSION}

\section{Tensile Strength}

Table 4 shows the result of the ultimate tensile strength (UTS) and fracture location for all laser-welded boron steel specimens. Welded sample with the lowest and highest UTS was selected for further analysis. Figure 3 shows the fractured location of the selected sample, which is from the lowest UTS (sample 1) and highest UTS (sample 9) which is 272.5 MPa and 445.7 MPa, respectively.

Table 4. Ultimate tensile strength results and fracture location.

\begin{tabular}{lccccc}
\hline Sample & $\begin{array}{c}\text { Peak power } \\
(\mathrm{W})\end{array}$ & $\begin{array}{c}\text { Welding } \\
\text { speed }(\mathrm{mm} / \mathrm{s})\end{array}$ & $\begin{array}{c}\text { Focal position } \\
(\mathrm{mm})\end{array}$ & $\begin{array}{c}\text { UTS } \\
(\mathrm{MPa})\end{array}$ & $\begin{array}{c}\text { Fracture } \\
\text { location }\end{array}$ \\
\hline 1 & 400 & 2.33 & 148 & 272.5 & Weld joint \\
2 & 500 & 2.33 & 148 & 416.6 & Base metal \\
3 & 400 & 2.83 & 148 & 440.4 & Base metal \\
4 & 500 & 2.83 & 148 & 435.4 & Base metal \\
5 & 400 & 2.58 & 144 & 410.9 & Weld joint \\
6 & 500 & 2.58 & 144 & 443.7 & Base metal \\
7 & 400 & 2.58 & 152 & 435.5 & Base metal \\
8 & 500 & 2.58 & 152 & 431.9 & Base metal \\
9 & 450 & 2.33 & 144 & 445.7 & Base metal \\
10 & 450 & 2.83 & 144 & 443.1 & Base metal \\
11 & 450 & 2.33 & 152 & 439.1 & Base metal \\
12 & 450 & 2.83 & 152 & 444.2 & Base metal \\
13 & 450 & 2.58 & 148 & 436.1 & Base metal \\
14 & 450 & 2.58 & 148 & 439.8 & Base metal \\
15 & 450 & 2.58 & 148 & 427.3 & Base metal \\
Base metal & - & - & - & 444 & Base metal \\
\hline
\end{tabular}

It was observed that the fracture occurred at the weld joint for sample 1 which shows that the weld area was not strong. It was a different situation with sample 9 where the fracture occurred at base metal which showed that the weld was strong, as the sample fractured at base metal. Welding efficiency was calculated to be $100.3 \%$ based on the tensile strength from Eq. (1) for sample $9(450 \mathrm{~W}, 2.33 \mathrm{~mm} / \mathrm{s}, 144 \mathrm{~mm})$ which was almost as strong as the base metal. It was observed that higher laser power with a lower value of focal position has resulted in stronger laser welded joint for boron steel.

Welding efficiency $=$ UTS of welded sample / UTS of base metal

\section{Weld Geometry}

Weld geometry was studied based on the weld cross-section area, selected from the stable condition of weld seam as shown in Figure 1 for the microstructure analysis section. The macrostructure images of all samples were compiled as shown in Figure 4. The weld geometry consists of base metal (BM), heat affected zone (HAZ), and fusion zone (FZ). 


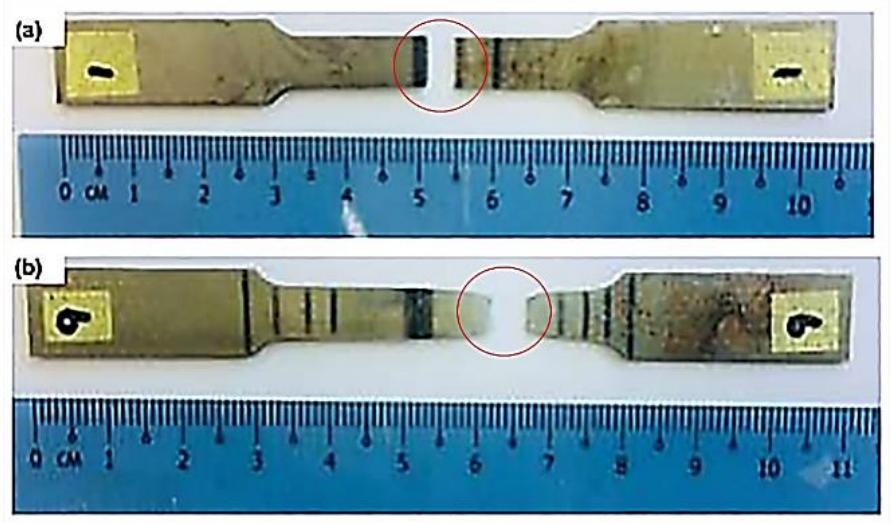

Figure 3. Fracture location of sample with (a) lowest UTS and (b) highest UTS.

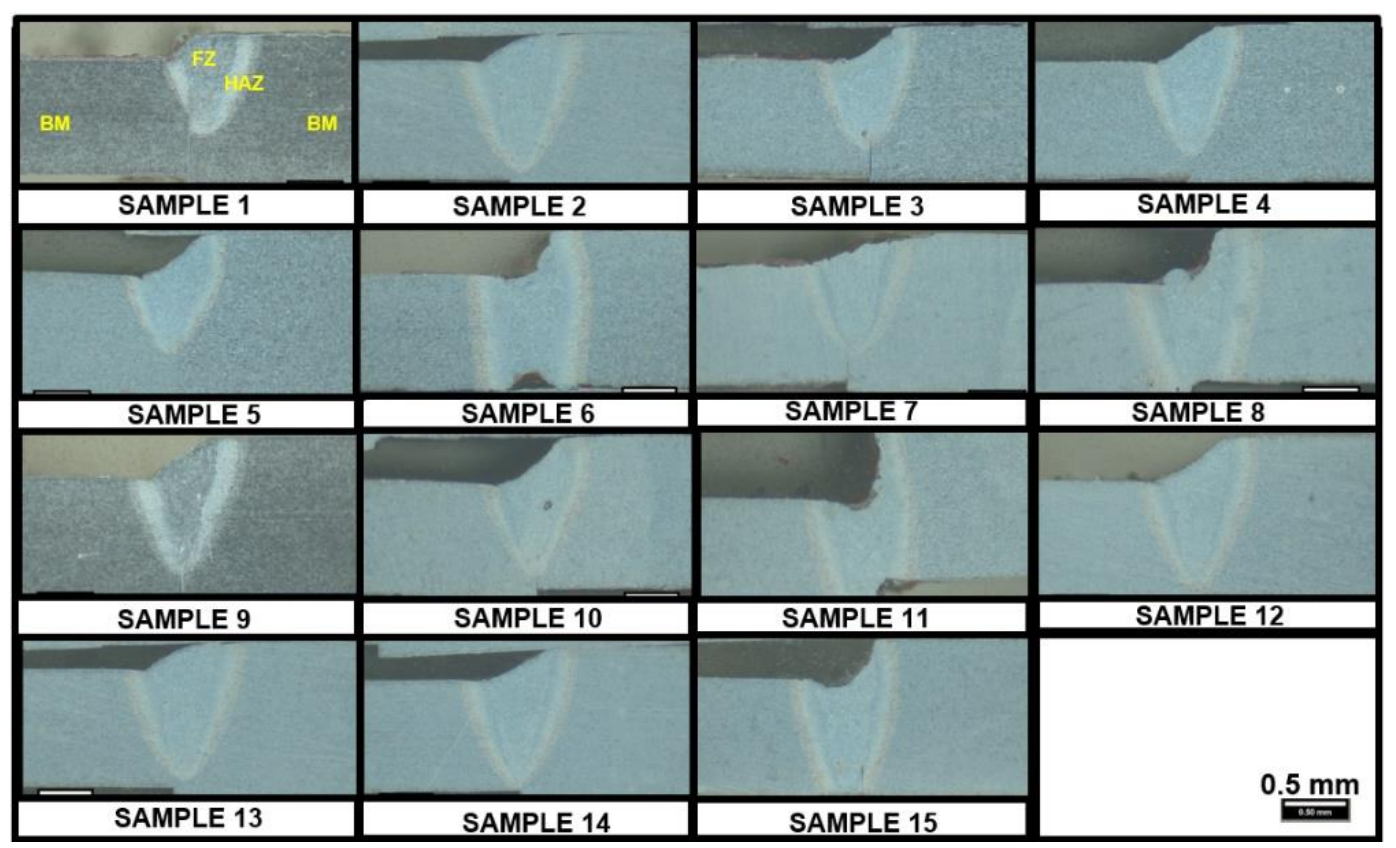

Figure 4. Macrostructure images of dissimilar thickness welded samples.

Figure 4 shows that sample 1, which was welded using lower peak power at 400 $\mathrm{W}$ at medium-high of focal position $(148 \mathrm{~mm})$, produced shallow weld geometry. Meanwhile, for the highest tensile strength value, sample 9 which was welded using a medium value of peak power $(450 \mathrm{~W})$ with minimum focal position $(144 \mathrm{~mm})$ possessed deeper weld penetration compared to sample 1 . This was due to the condition of heat concentration produced for welding sample 9 was higher compared to sample 1. Sample 12, 13, and 14 also had an almost similar UTS results to the base metal as the joint fractured at base metal. These samples were also welded with $450 \mathrm{~W}$ power at mediumhigh focal position (148 mm). 

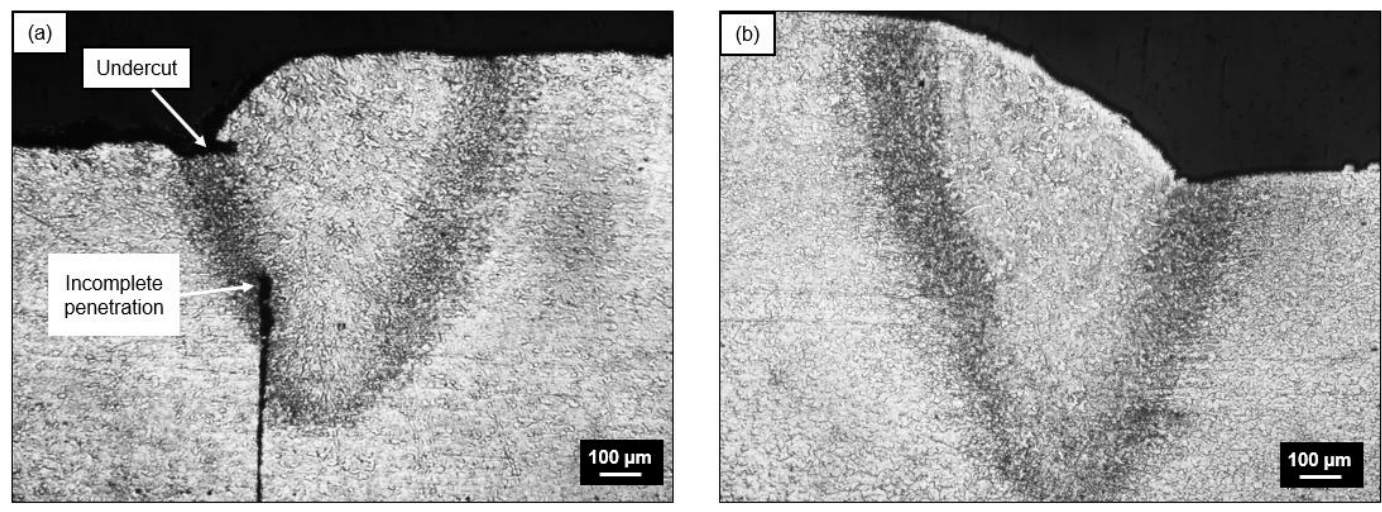

Figure 5. Cross-section region of (a) sample 1 and (b) sample 9.

Based on the observation, the welded sample with the highest and lowest tensile strength were selected to compare their weld geometry and microstructure behaviour. It showed that sample $1(400 \mathrm{~W}, 2.33 \mathrm{~mm} / \mathrm{s}, 148 \mathrm{~mm})$ had an incomplete penetration while sample $9(450 \mathrm{~W}, 2.33 \mathrm{~mm} / \mathrm{s}, 144 \mathrm{~mm})$ showed a complete penetration. Figure 5 shows the cross-sections of the welded area (optical microscope images) for each sample for better observation. From Figure 5(a), it was observed that the sample that was welded with lower power $(400 \mathrm{~W})$ and higher focal distance $(148 \mathrm{~mm})$ possessed incomplete weld penetration and undercut defects due to the lower heat input resulting from lower laser power used with lesser laser beam intensity onto the sample surface. Different situation observed in sample 9, as shown in Figure 5(b) where the sound weld produced with complete weld penetration. Free defect in the weld contributed to the higher joint strength.

\section{Aspect Ratio}

Based on the weld geometry observation, aspect ratio (AR) was calculated to determine the type of welding mode produced after being laser welded with different parameters. For the laser welding, welding mode can be determined as the weld in conduction or keyhole mode [13]. This ratio can also be related to the penetration ratio (PR) where it was used to calculate the ratio between the actual depth of weld penetration and thickness of the sample being welded. PR could be affected if there was undercut defects presented in the weld joint, even though full penetration was achieved [14]. The PR value that was equal or closer to 1 indicated higher effective penetration, less undercut defect, and led to greater strength. Equation (2), (3), and (4) shows the calculation of depth actual, PR, and AR, respectively to determine the type of weld geometry [15] produced for the lowest and highest tensile strength sample (sample 1 and 9, respectively).

$$
\text { Depth }_{\text {actual }}=\text { Depth - Undercut }
$$

$$
\text { Penetration Ratio }(\mathrm{PR})=\text { Depth }_{\text {actual }} / \text { Thickness }
$$

$$
\text { Aspect Ratio }(A R)=\text { Depth } / \text { Penetration }
$$

Based on calculation from Eq. (2), (3), and (4), results were tabulated as shown in Table 5. According to this table, the AR value for specimen 9 was higher than specimen 1. However, the AR values for both specimens were lower than 1 which indicated that the 
welding mode was the conduction mode, instead of keyhole profile. In addition, the result for specimen 1 had the lowest AR and PR due to its small amount of energy and PPD applied.

Table 5. Weld geometry details based on penetration and aspect ratio.

\begin{tabular}{lcccc}
\hline Sample & Width $(\mathrm{mm})$ & Depth $(\mathrm{mm})$ & Aspect ratio $(\mathrm{AR})$ & Penetration ratio (PR) \\
\hline 1 & 2.36 & 1.027 & 0.435 & 0.621 \\
9 & 3.44 & 1.521 & 0.442 & 0.811 \\
\hline
\end{tabular}

\section{Microstructure of the Highest UTS Sample}

Sample 9 possessed the highest UTS value where the parameters used were $450 \mathrm{~W}, 2.33$ $\mathrm{mm} / \mathrm{s}$, and $144 \mathrm{~mm}$ for peak power, welding speed, and focal position, respectively. Figure 6 shows the microstructure images for sample 9, which possessed the highest tensile strength captured by the optical microscope at four images at the weld area. Figure 6(a) shows the cross-section of the weld region of the sample. It was observed that there were 3 different regions which represented the transition of microstructures from base metal (BM) to fusion zone (FZ). It could be observed clearly from Figure 6(b) where the transition occurred from the BM to the FZ. Three different areas of BM, heat affected zone (HAZ), and FZ were observed. All three different regions have different microstructures.

Figure 6(c) shows the microstructure image at HAZ where it consisted of an irregular arrangement of martensites and finer grain size approximately at $11.3 \mu \mathrm{m}$ compared to the BM region since this region was affected by heat from laser beam during the laser welding process. Figure 6(d) shows the microstructure image at BM region. The microstructure in BM region is consisted of ferrite and pearlite grains structure, where they are the common general structures of steels [16]. The average grain size of base metal was found to be $45.5 \mu \mathrm{m}$. Figure 6 (e) then indicates the microstructure images at the fusion zone where it was observed that martensitic microstructure which was observed as needle-shaped grains produced at this region with the average grain size of $9.8 \mu \mathrm{m}$. It was found that the grain size at FZ was smaller compared to the BM and HAZ. This phenomenon was due to the solidification of molten pool started with the formation of austenite and the mixture of microstructure is formed depending on its cooling rate.

The post laser welded boron steel experienced a rapid cooling process due to the rapid cooling features of high strength steels after being heated by laser. Martensite grains in fusion zone were formed by austenite rapid cooling, which was resulted by the limited time of atom to diffuse out of the crystal structure to form pearlite. Moon et al. conducted a similar with the recent study [17]. They found that the uncoated boron steel welded by using laser produced martensite microstructure at fusion zone due to the rapid cooling features after being laser welded. It was justified that the sample fractured at base metal location due to the large grain size compared to the grain size of microstructure produced in $\mathrm{HAZ}$ and $\mathrm{FZ}$. 

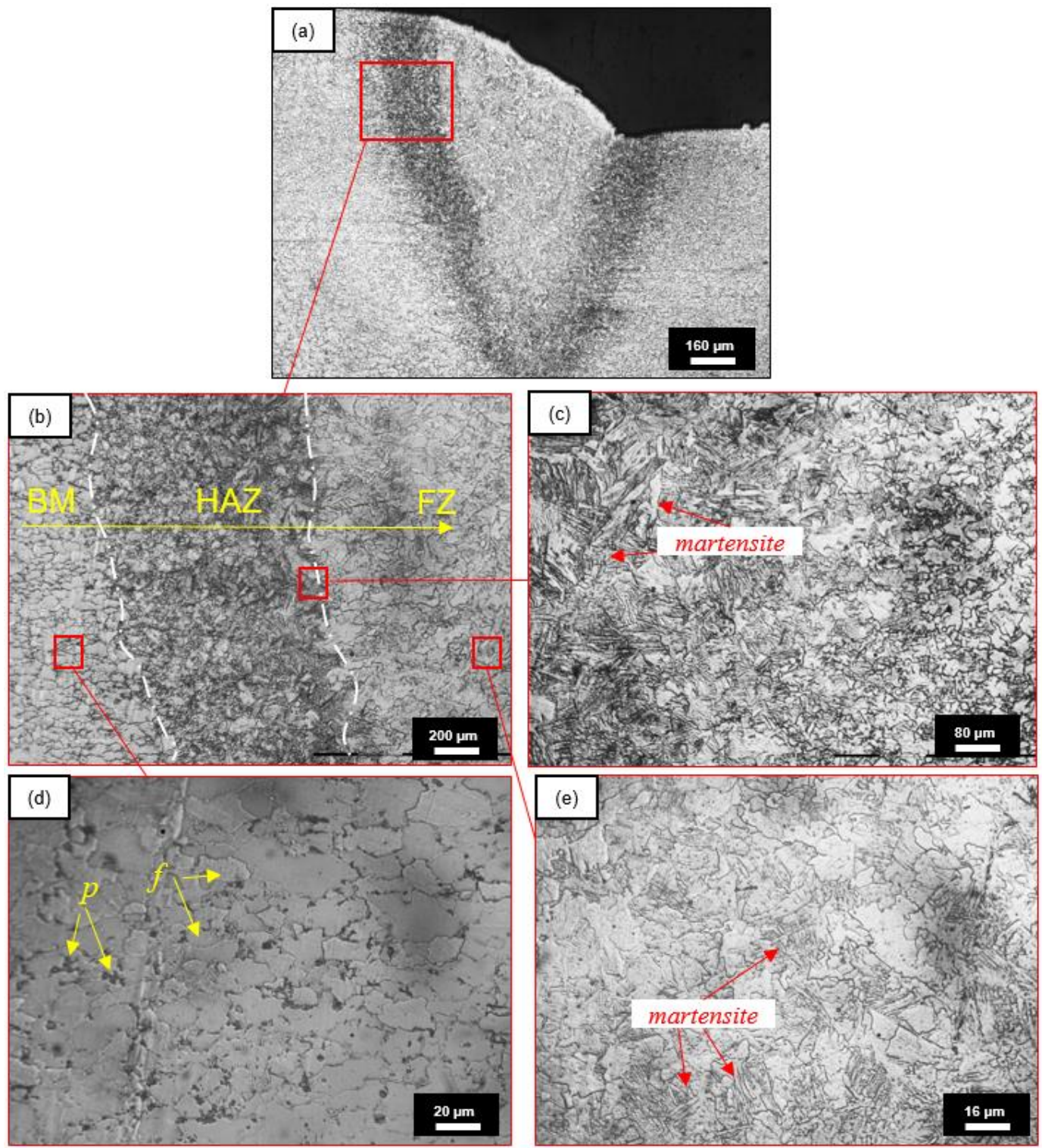

Figure 6. Cross section of sample 9 at weld area consist of (a) weld region, (b) transition region, (c) base metal, and (d) fusion zone.

\section{CONCLUSION}

According to the sets of the experiment from the design of experiment (DOE), sample 9 produced the highest ultimate tensile strength (UTS) of $445.7 \mathrm{MPa}$ and the fracture was located at the base metal. This phenomenon was due to the sufficient weld penetration produced for this sample, which was welded by $450 \mathrm{Watt}, 2.33 \mathrm{~mm} / \mathrm{s}$, and $144 \mathrm{~mm}$ of peak power, welding speed, and focal length, respectively. On the other hand, Specimen 1 produced the lowest UTS of $272.5 \mathrm{MPa}$. The fracture was located at the heat affected zone (HAZ) due to the insufficient penetration, which led to a weaker joint strength. In contrast, sample 1 was welded by $400-W a t t, 2.33 \mathrm{~mm} / \mathrm{s}$ and $148 \mathrm{~mm}$ of peak power, welding speed, and focal length, respectively.

Secondly, for the range of parameters, it was concluded that the peak power and focal position affected the tensile strength while welding speed did not affect the joint strength too much in this recent work. Higher peak power with lower focal length 
produced higher joint strength. Lastly, based on the geometrical features, the larger area of FZ contributed to the higher joint strength due to the fine martensitic microstructure was formed. Meanwhile, incomplete penetration led to the lower joint strength as it is categorised as one of the welding defects for insufficient penetration.

\section{ACKNOWLEDGEMENT}

The author would like to thank the technical staff of Universiti Malaysia Pahang for all of the work by providing laboratory facilities within which the experiments were conducted. Also, financial support by the Ministry of Education through Universiti Malaysia Pahang for research grant RDU180314 and RDU1803171 is gratefully acknowledged.

\section{REFERENCES}

[1] Sharma DP. Manufacturing Science-I: Welding. Gate 2017: Mechanical Engineering. 3rd ed. Delhi: PHI Learning Pvt. Ltd.; 2017.

[2] Yusof MFM, Kamaruzaman MA, Zubair M, Ishak M. Detection of defects on weld bead through the wavelet analysis of the acquired arc sound signal. Journal of Mechanical Engineering and Sciences, 2016; 10(2): 2031-2042.

[3] Abdullah K, Wild PM, Jeswiet JJ, Ghasempoor A. Tensile testing for weld deformation properties in similar gage tailor welded blanks using the rule of mixtures. Journal of Materials Processing Technology, 2001; 112(1): 91-97.

[4] Merklein M, Wieland M, Lechner M, Bruschi S, Ghiotti A. Hot stamping of boron steel sheets with tailored properties: a review. Journal of Materials Processing Technology, 2016; 228(1): 11-24.

[5] Odabaş1 A, Ünlü N, Göller G, Eruslu MN. A study on laser beam welding (LBW) technique: effect of heat input on the microstructural evolution of superalloy Inconel 718. Metallurgical and Materials Transactions A, 2010; 41(9): 23572365.

[6] Salleh MNM, Ishak M, Quazi MM, Aiman MH. Microstructure, mechanical, and failure characteristics of laser-microwelded AZ31B Mg alloy optimized by response surface methodology. The International Journal of Advanced Manufacturing Technology, 2018; 1-17.

[7] Assuncao E, Williams S. Comparison of continuous wave and pulsed wave laser welding effects. Optics and lasers in Engineering, 2013; 51(6): 674-680.

[8] Easterling K. Introduction to the physical metallurgy of welding: Elsevier; 2013.

[9] Pitscheneder W, DebRoy T, Mundra K, Ebner R. Geometry during Multikilowatt Laser Beam Welding of Steels. Weld J, 1996; 75(3): 71-80.

[10] Liao YC, Yu MH. Effects of laser beam energy and incident angle on the pulse laser welding of stainless steel thin sheet. Journal of materials processing technology, 2007; 190(1-3): 102-108.

[11] Salleh MNM, Ishak M, Double fillet lap of laser welding of thin sheet AZ31B Mg alloy. In: 1st Joining and Welding Symposium,UMP, Pekan, Malaysia; 11 July 2017.

[12] Sun Z, Karppi R. The application of electron beam welding for the joining of dissimilar metals: an overview. Journal of Materials Processing Technology, 1996; 59(3): 257-267. 
[13] Tenner F, Brock C, Klämpfl F, Schmidt M. Analysis of the correlation between plasma plume and keyhole behavior in laser metal welding for the modeling of the keyhole geometry. Optics and Lasers in Engineering, 2015; 64(1): 32-41.

[14] Zhao Y, Zhang Y, Hu W, Lai X. Optimization of laser welding thin-gage galvanized steel via response surface methodology. Optics and Lasers in Engineering, 2012; 50(9): 1267-1273.

[15] Yaakob K, Ishak M, Idris S. The effect of pulse welding parameters on weld geometry of boron steel using low power fibre laser. Journal of Mechanical Engineering and Sciences, 2017; 11(3): 2895-2905.

[16] Bošnjak SM, Gnjatović NB, Momčilović DB, Milenović IL, Gašić VM. Failure analysis of the mobile elevating work platform. Case Studies in Engineering Failure Analysis, 2015; 3: 80-87.

[17] Moon JH, Seo PK, Kang CG. A study on mechanical properties of laser-welded blank of a boron sheet steel by laser ablation variable of Al-Si coating layer. International Journal of Precision Engineering and Manufacturing, 2013; 14(2): 283-288. 